\title{
The Effects of Gonadotropin Replacement Therapy on Metabolic Parameters and Body Composition in Men with Idiopathic Hypogonadotropic Hypogonadism
}

\author{
Authors \\ F. Bayram ${ }^{1}$, G. Elbuken ${ }^{1}$, C. Korkmaz ${ }^{1}$, A. Aydogdu ${ }^{2}$, Z. Karaca ${ }^{1}$, I. Cakır ${ }^{1}$ \\ Affiliations \\ ${ }^{1}$ Department of Endocrinology and Metabolism Kayseri, Erciyes University Medical School, Kayseri, Turkey \\ ${ }^{2}$ Department of Endocrinology and Metabolism Ankara, Gulhane School of Medicine, Ankara, Turkey
}

\author{
Key words \\ - idiopathic hypogonado- \\ tropic hypogonadism \\ - metabolic syndrome \\ - gonadotropin replacement \\ therapy
}

\section{Abstract \\ $\nabla$}

Testosterone replacement therapy (TRT) in idiopathic hypogonadotrophic hypogonadism (IHH) slows the process of metabolic syndrome (MetS), diabetes mellitus, and cardiovascular diseases by its inversing effects on insulin resistance, dyslipidemia, and blood pressure. Since there are not enough data regarding the effects of gonadotropin replacement therapy (GRT), we aimed to investigate the impact of GRT on MetS parameters in IHH patients. Sixteen patients with $\mathrm{IHH}$ and 20 age and body mass index (BDI)-matched healthy controls were enrolled into the study. Patients were evaluated at baseline and 6 months after the GRT. Sex hormones, insulin like growth factor-1, prolactin, insulin, C-reactive protein (CRP), homocysteine, and lipid levels were measured at baseline and after the treatment. Anthro-

\section{Introduction}

second revision 21.09.2015

\section{Bibliography}

DOI http://dx.doi.org/

10.1055/s-0035-1564252

Published online:

October 20, 2015

Horm Metab Res 2016;

48: 112-117

(c) Georg Thieme Verlag KG

Stuttgart - New York

ISSN 0018-5043

\section{Correspondence}

\section{A. Aydogdu}

Department of Endocrinology and Metabolism

Gulhane School of Medicine 06018 Ankara

Turkey

Tel.: + 90/312/3044212

Fax: + 90/312/3044 201

draydoganaydogdu@gmail.com
Hypogonadotropic hypogonadism $(\mathrm{HH})$ is a state of impaired testosterone secretion, which is due to a malfunction at either hypothalamic or pituitary level. $\mathrm{HH}$ is diagnosed in patients with low testosterone levels in the presence of low or normal gonadotropin concentrations [1]. In the absence of an identifiable cause of $\mathrm{HH}$, it is called IHH [2]. The common consequences of male hypogonadism include decreased libido, erectile dysfunction, decreased muscle mass, osteoporosis, increased fat mass, loss of energy, changes in mood, and decreased secondary sex characteristics (especially decreased sexual hair) [3].

Testosterone replacement therapy is the most widely used treatment in patients with hypogonadism for inducing/preserving secondary sexual characteristics and sexual function. In subjects with $\mathrm{HH}$, gonadotropins may be used instead of testosterone therapy, especially to pro- pometric measurements, including BMI, body fat ratio (BFR), fat free mass (FFM), waist circumference, and waist-to-hip ratio (WHR), were also performed. Homeostasis Model Assessment of Insulin Resistance (HOMA-IR) index was calculated. Body fat ratio, triglyceride, HOMA-IR, and CRP levels were higher, whereas bone age, fat free mass, and creatinine levels were lower in the patients with hypogonadism. HOMA-IR indices and basal insulin levels decreased significantly after 6 months of GRT compared with baseline levels. Triglyceride levels, and BFRs diminished significantly by an accompanying decline in WHR. FFM of the patients increased following the GRT. No significant changes were detected in CRP, homocysteine, total and LDL-cholesterol levels. Similar to TRT, hCG treatment decreases HOMA-IR, triglyceride levels, BFR and WHRs, and increases FFM in patients with IHH.

vide fertility by induction of both hormonogenesis and spermatogenesis [4]. Gonadotropin therapy is initiated with human chorionic gonadotropin (hCG) alone, which may be sufficient to stimulate spermatogenesis and fertility, and if fertility cannot be achieved with hCG, FSH is added to hCG therapy. Treatment regimen is switched back to testosterone substitution following successful fertilization [2].

Hypogonadism is suggested to be one of the underlying causes of the metabolic syndrome (MetS) [5]. According to recent studies the association between the low testosterone levels and MetS was independent of BMI, and it was reported as an independent risk factor for type 2 diabetes mellitus (DM) [4,6-8]. Current epidemiological data indicated negative correlations between testosterone, total cholesterol, low-density lipoprotein (LDL) cholesterol, and triglyceride levels, whereas a positive association was found between testosterone and high-density 
lipoprotein (HDL) cholesterol levels [8,9]. Because of the relationship with diabetes, MetS, inflammation and dyslipidemia; low testosterone level is accepted as a novel cardiovascular risk factor, besides the other already-known ones [10]. Low testosterone levels were inversely linked to coronary atherosclerosis [8-11], and associated with increased cardiovascular and all cause mortality $[12,13]$. TRT was shown not only to improve the symptoms of hypogonadism but also to recover the insulin resistance, dyslipidemia, and hypertension. Therefore, testosterone replacement therapy (TRT) has some potency to slow the process of DM and cardiovascular diseases by its positive effects on MetS components $[11,13]$.

Although the positive effects of TRT on MetS have already been recognized, the positive or negative impact of GRT on MetS has not been addressed sufficiently, especially in prospective studies. The aim of the present study was to evaluate the effects of hCG treatment on MetS parameters, insulin resistance, and body composition in men with $\mathrm{IHH}$.

\section{Materials and Methods}

\section{$\nabla$}

\section{Study design and patient selection}

Sixteen male patients with IHH (mean age $27.5 \pm 10.5$ years, range $17-48$ years) and 20 healthy controls were included in the study. All patients were diagnosed according to clinical findings of hypogonadism (such as low testis volumes, decreased body and facial hair, delayed puberty, eunochoidal stature), subnormal testosterone levels in the presence of low or normal gonadotropins. Patients were excluded if they had any other hormonal and systemic disease, or if they used any medication for hypogonadism in the last 6 months preceding the replacement therapy. The participants of the control group were selected among healthy males who were referred to the Outpatient Clinic of Endocrinology and Metabolism for check-up. All patients and controls gave written informed consent and the local research ethics committee approved the protocol.

\section{Patients}

The onset of IHH was before the onset of puberty in all patients. Three patients desired fertility. Only one patient had received fertility treatment with GRT for 6 months and had a child before the start of the study. This patient had not been treated for IHH during the past one year. The remaining 15 patients were naive for GRT. None of the participants had any contraindication to GRT.

\section{Treatment and follow-up procedures}

The patients were treated with human chorionic gonadotropin (hCG) as a substitution for LH. Intramuscular injections of hCG 1500 IU were administered 3 times weekly in duration of 6 months. Physical examination measurement of height, weight, headpubis and pubis-heel ratio, body mass index (BMI), pattern of axillary and pubic hair, penis size, and testes volumes were recorded. Thyroid, breast, ophtalmological, and smelling examinations were also performed. Penile size was measured in centimeters of length and testicular size was measured by a Prader orchiometer. The basal (fasting) insulin level, Homeostasis Model Assessment of Insulin Resistance (HOMA-IR) index, lipid profile, body fat ratio (BFR), body mass index (BMIs), waist circumference, waist-to-hip ratio (WHRs), homocysteine level, and C-reactive protein (CRP) were assessed prior to and following GRT. Their bone ages were also calculated.
Heights and body weights were measured in centimeter $(\mathrm{cm})$ and kilogram (kg) in all patients, respectively. BMI was calculated by using the equation [BMI = weight $(\mathrm{kg}) /$ height $\left.^{2}\left(\mathrm{~m}^{2}\right)\right]$. Minimum waist (W) circumference (in centimeters; minimum circumference between the lower rib margin and the iliac crest, mid-waist) and maximum hip ( $\mathrm{H}$ ) circumference (in centimeters; the widest diameter over the greater trochanters) were measured while the subjects were standing with their heels together. Waist-to-hip ratio (WHR) was calculated by proportioning waist circumference $(\mathrm{cm})$ to hip circumference $(\mathrm{cm})$. Body composition including fat-free mass and percentage body fat for each patient were measured in the fasting state by TANITA BF-300 ${ }^{\circledR}$ body fat analyzer (TANITA Corporation, Tokyo, Japan). All measurements were repeated after 6 months of hCG treatment.

\section{Laboratory and other measurements}

Bone age was determined by radiological examinations of the left hand wrist in all patients and controls before and after hCG treatment. All patients were evaluated by pituitary magnetic resonance imaging (MRI) to exclude any anatomical lesions.

\section{Biochemical tests}

All blood samples were obtained in the morning after an overnight fast. Complete blood count, erythrocyte sedimentation rate, fasting blood glucose, blood urea nitrogen, creatinine, uric acid, total protein, albumin, aspartate aminotransferase, and alanine aminotransferase tests were drawn from all patients and control group (data are not shown).

Serum total and HDL-cholesterol, and triglyceride levels were measured by enzymatic reactions using Olympus AU 2700 auto analyzer (Olympus Diagnostics, GmbH, Hamburg, Germany). LDLcholesterol levels were calculated by Friedewald's formula [14].

Glucose levels were determined by glucose oxydase method (ADVIA 1800, Siemens Medical Solutions Diagnostics, Tarrytown, NY, USA). Following a free carbohydrate diet for 3 days, all patients underwent a $75 \mathrm{~g}$ oral glucose tolerance test (OGTT) after an overnight fasting at baseline and 6 months after the hCG treatment. Insulin levels at $0,30,60,90,120 \mathrm{~min}$ of OGTT were measured synchronously with the glucose levels. Insulin was measured by an enzyme immunoassay kit (ADVIA Centaur Insulin IRI, Siemens Medical Solutions Diagnostics, Tarrytown, NY, USA).

Homeostasis model assessment of insulin resistance was calculated (fasting plasma glucose level $(\mathrm{mmol} / \mathrm{l}) \times$ fasting insulin level $(\mu \mathrm{IU} / \mathrm{ml}) / 22.5)$. Subjects with a HOMA-IR score of $\geq 2.7$ were considered as having insulin resistance $[12,15]$.

Homocysteine levels were measured by high-performance liquid chromatography (HPLC) with fluorescence detection (Chromosystems, Germany) and CRP levels were measured by an ultrasensitive method (Human CRP lumELISA Kit, Ultra Sensitive, Calbiotech, Inc., CA, USA).

Basal hormone levels were measured by commercially available kits using a chemiluminesence method for FSH (ACS:180, Bayer, Germany; ref. range for men: 1.4-8.1 mIU/ml), LH (ACS:180, Bayer, Germany; ref. range for men: $1.5-9.3 \mathrm{mIU} / \mathrm{ml}$ ), estradiol (ACS:180, Bayer, Germany; ref. range for men: 0-52 pg/ml), prolactin (PRL) [ACS:180, Bayer, Germany; ref. range for men: $2-18 \mathrm{ng} / \mathrm{ml}$ ] and a radioimmunoassay method for free testosterone (Biosource, Nivelles, Belgium; ref. range for men: 8.9$42.5 \mathrm{ng} / \mathrm{dl}$ ), total testosterone (Biosource, Nivelles, Belgium; ref. range for men: 134-625 ng/dl), TSH (Biosource, Nivelles, Belgium; ref. range for men: $0.2-4.5 \mu \mathrm{IU} / \mathrm{ml}$ ), and IGF-1 (Biosource, Nivelles, Belgium; ref. range: $107-310 \mathrm{ng} / \mathrm{ml}$ ). 


\begin{tabular}{|lccccc|} 
Variables & Control group & Before therapy & After therapy & p1-Values & p2-Values \\
\hline Age $($ years $)$ & $24.6 \pm 2.0$ & $27.5 \pm 10.5$ & - & 0.225 & - \\
\hline Height $(\mathrm{cm})$ & $175.9 \pm 5.2$ & $175.3 \pm 12.8$ & $176.2 \pm 11.5$ & 0.422 & $0.008^{*}$ \\
\hline Weight $(\mathrm{kg})$ & $75.7 \pm 7.9$ & $79.3 \pm 19.5$ & $80.6 \pm 17.4$ & 0.211 & 0.220 \\
BMI $\left(\mathrm{kg} / \mathrm{m}^{2}\right)$ & $24.5 \pm 3.1$ & $25.7 \pm 4.6$ & $25.7 \pm 4.7$ & 0.404 & 0.920 \\
\hline Waist circumference $(\mathrm{cm})$ & $78.3 \pm 5.8$ & $93.3 \pm 16.1$ & $92.3 \pm 15.5$ & $0.004^{*}$ & 0.119 \\
Waist to hip raito & $0.82(0.75-0.90)$ & $0.84(0.68-1.09)$ & $0.81(0.68-0.81)$ & 0.417 & $0.004^{*}$ \\
\hline Body fat ratio $(\%)$ & $17.6 \pm 5.8$ & $23.5 \pm 8.6$ & $20.2 \pm 8.4$ & $0.033^{*}$ & $0.019^{*}$ \\
\hline Fat-free mass $(\mathrm{kg})$ & $62.2 \pm 6.3$ & $60.6 \pm 12.1$ & $63.4 \pm 10.3$ & 0.042 & $<0.001^{*}$ \\
\hline Bone age (years) & $20 \pm 0.0$ & $16.3 \pm 2.1$ & $17.1 \pm 1.5$ & $0.0001^{*}$ & $0.01^{*}$ \\
\hline
\end{tabular}

Table 1 Comparison of the effects of GRT on body composition in patients with $\mathrm{IHH}$.

p1: Patients vs. controls; p2: Pretreatment vs. post-treatment; BMI: Body mass index

* Statistically significant $(p<0.05)$

\begin{tabular}{|c|c|c|c|c|c|c|}
\hline Variables & Control group & Before therapy & After therapy & p1-Values & p2-Values & Table 2 Metabolic parameters \\
\hline Basal (fasting) glucose (mg/dl) & $83.9 \pm 7.2$ & $83.5 \pm 7.0$ & $82.8 \pm 6.7$ & 0.814 & 0.753 & \\
\hline Glucose $2 \mathrm{~h}$ after OGTT (mg/dl) & - & $101.4 \pm 17.6$ & $89.9 \pm 14.1$ & - & $0.038^{*}$ & \\
\hline Basal insulin $(\mu \mathrm{lU} / \mathrm{ml})$ & $6.6 \pm 3.2$ & $30.0 \pm 27.3$ & $21.9 \pm 26.1$ & $<0.001^{*}$ & $0.003^{*}$ & \\
\hline HOMA-IR & $1.2 \pm 0.7$ & $6.1 \pm 5.4$ & $4.4 \pm 5.3$ & $<0.001 *$ & $0.005^{*}$ & \\
\hline AUC glucose (mg/dl) & - & $12678.8 \pm 1452$ & $13062.8 \pm 1685$ & & 0.271 & \\
\hline AUC insulin $(\mu \mathrm{lU} / \mathrm{ml})$ & - & $9066.3 \pm 5357$ & $7389.1 \pm 6209$ & & $0.006^{*}$ & \\
\hline Triglyceride (mg/dl) & $77.4 \pm 35.3$ & $124.8 \pm 51.0$ & $98.6 \pm 49.1$ & $0.004^{*}$ & $0.036^{*}$ & \\
\hline Total cholesterol (mg/dl) & $154.4 \pm 28.4$ & $190.63 \pm 53.07$ & $171.44 \pm 41.13$ & $0.022^{*}$ & 0.059 & \\
\hline LDL-cholesterol (mg/dl) & $94.0 \pm 23.5$ & $116.8 \pm 53.8$ & $106.1 \pm 33.5$ & 0.222 & 0.228 & \\
\hline HDL-cholesterol (mg/dl) & $43.1 \pm 7.4$ & $48.88 \pm 15.49$ & $46.00 \pm 14.26$ & 0.154 & 0.604 & \\
\hline CRP (mg/l) & $1.3(0.2-5)$ & $3.2(3.0-18.2)$ & $3.2(3.0-8.2)$ & $<0.001^{*}$ & 0.529 & \\
\hline AST (U/I) & $14.9 \pm 2.5$ & $16.1 \pm 9.9$ & $15.9 \pm 4.8$ & 0.498 & 0.413 & \\
\hline $\operatorname{ALT}(\mathrm{U} / \mathrm{I})$ & $20.5 \pm 4.3$ & $20.1 \pm 4.0$ & $19.7 \pm 4.3$ & 0.648 & 0.832 & \\
\hline $\mathrm{Hb}(\mathrm{g} / \mathrm{dl})$ & $15.8 \pm 0.6$ & $13.4 \pm 1.0$ & $13.8 \pm 1.4$ & $<0.001^{*}$ & 0.232 & \\
\hline $\operatorname{Htc}(\%)$ & $46.8 \pm 1.9$ & $39.2 \pm 2.8$ & $40.2 \pm 4.0$ & $<0.001^{*}$ & 0.211 & \\
\hline Urea (mg/dl) & $27.5 \pm 4.9$ & $30 \pm 6.7$ & $28.4 \pm 5.2$ & 0.305 & 0.169 & \\
\hline Creatinine (mg/dl) & $1.0 \pm 0.1$ & $0.8 \pm 0.0 .1$ & $0.8 \pm 0.1$ & $<0.001^{*}$ & 0.367 & \\
\hline Homocysteine $(\mu \mathrm{mol} / \mathrm{l})$ & - & $13.0 \pm 5.0$ & $11.4 \pm 4.2$ & - & 0.315 & \\
\hline
\end{tabular}

Patients were evaluated with hCG (Pregnyl-Organon) stimulation test before and after GRT. An amount of 1500 IU hCG was given via intramuscular injection once a day for 3 consecutive days. On the $4^{\text {th }}$ day, blood samples were drawn to measure serum levels of free and total testosterone. If the increments in free and total testosterone levels were more than $50 \%$ from the baseline it was accepted as gonadotropin deficiency [16].

\section{Statistical analysis}

All statistical analyses were performed using the Statistical Package for Social Sciences version 16.0 for Windows ${ }^{\circledR}$ system (SPSS $^{\circledR}$ Inc., Chicago, IL, USA). The normality of distribution of continuous variables was evaluated using the Shapiro-Wilk test. Changes in parameters during treatment were analyzed by paired $t$-test for normally distributed data and by Wilcoxon signed rank test if no normal distribution was evident. Linear relationship between variables was assessed by the Pearson correlation test for normally distributed data. Otherwise, the Spearman correlation test was applied. Results were presented as mean \pm SD for normally distributed data and as median (minmax) in case of significant deviation from normality, and categorical variables were expressed as numbers. All statistical tests were 2 -sided and statistical significance was set at p-value less than 0.05 .

\section{Results}

\section{Baseline characteristics}

The demographic, body composition and biochemical parameters of patients $(n=16)$ and healthy controls $(n=20)$ are displayed in $\odot$ Table $\mathbf{1 , 2}$. The 2 groups were similar with regard to age and BMI, but the bone age of the patients was significantly lower. Waist circumference and body fat ratio of the patients were significantly higher, but there was no significant difference in terms of waist-to-hip ratio. Basal insulin, HOMA-IR, AUC insulin, triglyceride, total cholesterol and CRP levels were significantly higher in patients with IHH ( $<<0.05$, for each one), whereas fasting plasma glucose, LDL cholesterol, and HDL cholesterol were similar between the groups ( $\bullet$ Table 2 ). Total testosterone, free testosterone, prolactin and estradiol levels were significantly lower in the patient group, however there was no difference in IGF1 levels ( $\bullet$ Table 3 ). There was no significant difference in total body fat free mass in hypogonadal patients compared with healthy controls.

Baseline vs. post-treatment demographics, biochemical parameters, Tanner stages and testicular volume

The mean chronological age of the patients was $27.5 \pm 10.5$ years, whereas their mean bone ages were significantly retarded with 
Table 3 Basal hormone levels and testosterone response to LH stimulation test at baseline and after GRT.

\begin{tabular}{|c|c|c|c|c|c|c|}
\hline Variables & & Control group & Before therapy & After therapy & p1-Values & p2-Values \\
\hline \multirow[t]{2}{*}{ Basal testosterone } & Total testosterone (ng/dl) & $550(387-982)$ & $39(8-158)$ & $512(207-1209)$ & $<0.001^{*}$ & $<0.001^{*}$ \\
\hline & Free testosterone $(\mathrm{pg} / \mathrm{ml})$ & $17.8 \pm 5.8$ & $2.5 \pm 1.5$ & $18.2 \pm 8.6$ & $<0.001^{*}$ & $<0.001^{*}$ \\
\hline \multirow{2}{*}{$\begin{array}{l}\text { Testosterone on } 4^{\text {th }} \text { day } \\
\text { after LH stimulation test }\end{array}$} & Total testosterone (ng/dl) & & $140.5(14.0-427.0)$ & $512(372-1273)$ & & $<0.001^{*}$ \\
\hline & Free testosterone $(\mathrm{pg} / \mathrm{ml})$ & & $7.6 \pm 6.3$ & $21.4 \pm 11.4$ & & $<0.001^{*}$ \\
\hline \multirow{5}{*}{$\begin{array}{l}\text { Testosterone on } 5^{\text {th }} \text { day } \\
\text { after LH stimulation test }\end{array}$} & Total testosterone (ng/dl) & & $170.5(12-1474)$ & $558(401-1273)$ & & $0.002^{*}$ \\
\hline & Free testosterone $(\mathrm{pg} / \mathrm{ml})$ & & $10.6 \pm 12.9$ & $24.3 \pm 14.0$ & & $0.002^{*}$ \\
\hline & Prolactin (ng/dl) & $6.2(3-12)$ & $3.6(1.1-11.0)$ & $5.4(0.6-15.8)$ & $0.043^{*}$ & $0.008^{*}$ \\
\hline & IGF-1 (ng/dl) & $437 \pm 79.7$ & $370.1 \pm 176.4$ & $474.5 \pm 200.8$ & 0.111 & $0.019^{*}$ \\
\hline & Estradiol (pg/ml) & $32.7 \pm 14.4$ & $22.9 \pm 15.5$ & $42.3 \pm 27.5$ & $0.045^{*}$ & $0.013^{*}$ \\
\hline
\end{tabular}

p1: Patients vs. controls; p2: Pretreatment vs. post-treatment. LH: Luteinizing hormone; IGF-1: Insulin like growth factor 1

* Statistically significant $(p<0.05)$
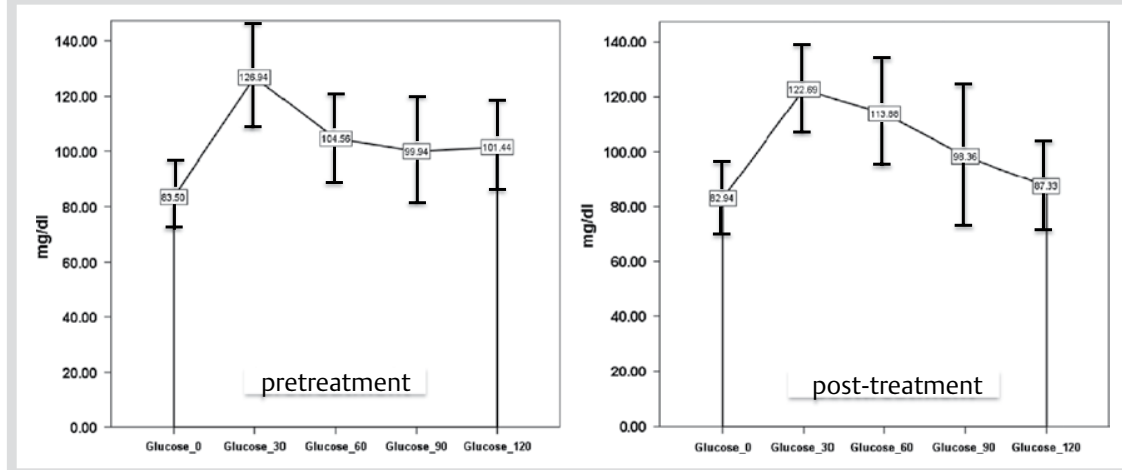

Fig. 1 Glucose tolerance test curves for glucose before and after treatment with hCG.

a mean of $16.3 \pm 2.1$ years $(p=0.0001)$. The anthropometric measurements are shown in $\bullet$ Table 1 . The mean height, bone age $(16.3 \pm 2.1$ vs. $17.1 \pm 2.5, p=0.03)$, testis volumes ( $3.6 \pm 0.7$ vs. $9.1 \pm 3.4, p=0.0001)$ and penile lengths $(3.6 \pm 0.7$ vs. $7.9 \pm 1.5$, $\mathrm{p}=0.0001$ ) of the patients increased significantly following the treatment. The BFRs significantly decreased in the patient group. Although the mean waist circumference tended to decrease after GRT, it was not statistically significant. However, GRT resulted in a significant reduction in the WHR and in a significant increase in the total body fat-free mass.

Basal and free testosterone and LH-stimulated total testosterone levels were elevated significantly following GRT. PRL, estradiol, and IGF-1 levels also increased significantly after the therapy ( 0 Table 3). Two of the 3 patients achieved their desired fertility. Eleven (69\%) patients had gynecomastia at baseline, which continued after the GRT. The remaining 5 patients developed no gynecomastia during the treatment period.

Basal insulin and AUC of insulin responses to OGTT declined after the GRT. Although basal fasting glucose levels unchanged, a significant decrease was detected in the $120^{\text {th }}$ minute of OGTT, besides improved HOMA-IR indices ( $\bullet$ Table 3 ). Although pretreatment HOMA-IR index did not correlated with homocysteine, post-treatment HOMA-IR index was positively correlated (r: 0.76, p: 0.001).

HOMA-IR, basal insulin, 2-h OGTT glucose, AUC insulin, triglyceride levels decreased significantly, whereas there were no significant differences in glucose, AUC glucose, total LDL, HDL-cholesterol, CRP, and homocysteine levels after the hCG replacement ( $\odot$ Table 2 ) ( $\odot$ Fig. 1,2).

Pretreatment HDL-cholesterol levels negatively correlated with WHR and waist circumference ( $\mathrm{r}:-0.52$, $\mathrm{p}: 0.039$, and $\mathrm{r}=-0.50$, $\mathrm{p}=0.047$, respectively). Pretreatment HDL-cholesterol levels also negatively $(\mathrm{r}=-0.716, \mathrm{p}=0.002)$ correlated with pretreatment BFR. Post-treatment HDL-cholesterol levels were negatively correlated with post-treatment waist circumference $(r=-0.54$, $\mathrm{p}=0.03)$ and post-treatment BFR $(\mathrm{r}=-0.73, \mathrm{p}=0.01)$, but not with WHR ( $=0.07)$. 


\section{Discussion}

$\checkmark$

Current data indicate that insulin resistance is more frequent among men with IHH compared with the general population and TRT improves life expectancy, reduces risk of developing MetS, other cardiovascular risk factors and type 2 DM [6,9,17$20]$ in patients with hypogonadism. There are some contradictory trials in the literature about the benefits of TRT on glucose metabolism and insulin resistance. Although testosterone administration was not shown to be effective on insulin resistance in men who had testosterone levels within physiological limits [21], TRT was found to increase glucose uptake in muscles and to be associated with decreased fasting plasma insulin levels, insulin resistance and improved A1c levels in patients with hypogonadism $[19,20,22]$. On the contrary, androgen deprivation therapy, which is used for prostate cancer, has been shown to increase plasma insulin levels [23]. Testosterone is thought to act on insulin resistance through specific pathways involved in hormone secretion from adipose tissue [24]. In the present study, GRT resulted in significant decreases in HOMA-IR indices, basal insulin levels and glucose concentrations in the $120^{\text {th }}$ minute of OGTT. The improved insulin sensitivity following GRT is presumably due to increased testosterone levels.

Testosterone replacement therapy was shown to have some positive effects on lipid profile. Kapoor et al. have found that TRT decreases total cholesterol and increases HDL-cholesterol levels significantly in 24 type 2 diabetic patients with IHH [17]. In contrast, androgen deprivation therapy has been shown to increase plasma total, LDL, HDL-cholesterol and triglyceride levels [23]. Although we could not find any difference in total and LDL-cholesterol, triglyceride levels significantly decreased after the replacement therapy. Similar to our results, in a previous study, treatment with hCG for 6 months caused no significant difference in total, LDL, HDL-cholesterol levels, whereas a significant decrease was reported in triglyceride levels [25].

We found significant decreases in both WHR and BFR after hCG treatment. Improvement in body composition after GRT occurs presumably via elevated testosterone levels. Androgens inhibit adipogenesis and lead to myogenic differentiation of mesenchymal pleuripotent cells through androgen receptor-mediated pathway. Sex steroid hormones act on adipose tissue by both genomic and nongenomic mechanisms. Sex hormones activate the cAMP cascade and subsequently the activation of hormonesensitive lipase leads to lipolysis in adipose tissue [26]. Although fat tissue decreased there was no difference in body weight after testosterone treatment. We noticed an increase in fat-free mass (lean body mass) in patients with hypogonadism after GRT. The TANITA BF- $300^{\circledR}$ body fat analyzer is known to calculate the muscle tissue as the component free from the adipose tissue. In the previous studies it was shown that hCG treatment increases muscle tissue [27]. The increase in muscle tissue mass was supposed to be related to the androgen augmentation [28].

TRT was shown to decrease leptin and adiponectin levels in hypogonadal men with type 2 diabetes, without having a significant effect on CRP levels [24]. Another study revealed a reduction in CRP levels in men with hypogonadism treated with TRT [29]. In the present study, GRT resulted in a mild, but nonsignificant decrease in homocysteine and CRP, which is a proinflammatory cytokine. TRT alone was previously shown to decrease homocysteine levels more prominently than testoster- one plus phosphodiesterase inhibitor combination therapy [30]. In contrast Oktenli et al., showed an increase in homocysteine levels after 6 months of TRT in 35 men with IHH, which was independent from androgen levels [31]. The nonsignificant difference in CRP and homocysteine levels after GRT in our study may be related to the duration of GRT and the relatively low levels of endogenous testosterone after the hCG replacement, when compared to treatment with testosterone.

Although some improvement in the bone ages of the patients were observed after treatment, their bone ages were still retarded compared to their chronological ages, which can be explained by the short duration of GRT. Serum IGF-1 levels significantly increased following GRT. The increase was more striking in patients younger than 21 years. Former studies have indicated that both androgens and estrogens are able to increase IGF-1 levels [32,33]. It was thought that the elevation of IGF-1 levels was due to the effects of sex steroids on growth hormone, which were induced by the activation of hypothalamo-pituitary-gonadal axis in puberty. Sex steroids also were shown to stimulate IGF-1 levels by acting on the liver [34]. Even if GRT is continued for a longer duration after the physiological pubertal age, the elevated IGF-1 levels are found to correlate with height and bone age. Therefore, elevation of the IGF-1 levels might be related to androgenization at tissue level.

We detected a significant, but clinically irrelevant increase in PRL levels following GRT. Likewise, some case reports, which pointed out an elevation of serum PRL levels following TRT, may be probably through aromatization of testosterone to estrogen and stimulation of PRL secretion by estrogens $[35,36]$.

TRT may have some potential side effects including elevation of liver enzymes, progression of congestive heart failure, and elevation of hematocrit levels. And also it is contraindicated in patients with benign prostate hyperplasia and prostate carcinoma [37]. Previously, testosterone treatment was reported to cause a significant increase in hematocrit levels in patients with hypogonadism, however hCG treatment had no such effects. The same study showed that the testicular growth was predominant with hCG treatment [25]. Thanks to these beneficial effects, hCG treatment seems to be more physiological and safer.

This study has several limitations. Low patient number seems to be the main limitation in the present study. However, narrow selection criteria caused such a small number of patients. Accordingly, most of the previous studies on hypogonadism included small cohorts. Lack of a patient group treated with testosterone is another limitation of this study. Also, a 6-month follow-up period may not be sufficient to observe the long-term effects of hCG treatment. To our knowledge this is the first prospective study demonstrating the favorable effects of GRT on glucose metabolism and BFR in male patients with IHH, so our study gives important knowledge about the topic.

In conclusion, GRT plays important roles not only in sex differentiation and development, but also in glucose and fat metabolism. GRT decreases HOMA-IR, BFR, and WHRs in patients with IHH more physiologically than the TRT.

\section{Funding}

$\nabla$

This research did not receive any specific grant from any funding agency in the public, commercial, or not-for-profit sector. 


\section{Conflict of Interest}

\section{$\nabla$}

The authors declare no conflict of interest.

\section{References}

1 Layman LC. Hypogonadotropic hypogonadism. Endocrinol Metab Clin North Am 2007; 36: 283-296

2 Beg S, Al Khoury L, Cunningham GR. Testosterone replacement in men. Curr Opin Endocrinol Diabetes Obes 2008; 15: 364-370

3 Balasubramanian $V$, Naing $S$. Hypogonadism in chronic obstructive pulmonary disease: incidence and effects. Curr Opin Pulm Med 2012; 18: $112-117$

4 Pitteloud N, Mootha VK, Dwyer AA, Hardin M, Lee H, Eriksson KF, Tripathy D, Yialamas $M$, Groop L, Elahi D, Hayes FJ. Relationship between testosterone levels, insulin sensitivity, and mitochondrial function in men. Diabetes Care 2005; 28: 1636-1642

5 Zitzmann M. Testosterone deficiency, insulin resistance and the metabolic syndrome. Nat Rev Endocrinol 2009; 5: 673-681

6 Stellato RK, Feldman HA, Hamdy O, Horton ES, McKinlay JB. Testosterone sex hormone-binding globulin, and the development of type 2 diabetes in middle-aged men: prospective results from the Massachusetts male aging study. Diabetes Care 2000; 23: 490-494

7 Yesilova Z, Oktenli C, Sanisoglu SY, MusabakU, Cakir E, Ozata M,Dagalp K. Evaluation of insulin sensitivity in patients with Klinefelter's syndrome: a hyperinsulinemic euglycemic clamp study. Endocrine 2005; 27: $11-15$

8 Laaksonen DE, Niskanen L, Punnonen K, Nyyssonen K, Tuomainen TP, Salonen R, Rauramaa R, Salonen JT. Sex hormones, inflammation and the metabolic syndrome: a population-based study. Eur J Endocrinol 2003; 149: 601-608

9 Haffner SM, Mykkanen L, Valdez RA, Katz MS. Relationship of sex hormones to lipids and lipoproteins in nondiabetic men. J Clin Endocrinol Metab 1993; 77: 1610-1615

10 Maggio M, Basaria S. Welcoming low testosterone as a cardiovascular risk factor. Int J Impot Res 2009; 21: 261-264

11 Shabsigh R, Katz M, Yan G, Makhsida N. Cardiovascular issues in hypogonadism and testosterone therapy. Am J Cardiol 2005; 96: 67-72

12 Matthews DR, Hosker JP, Rudenski AS, Naylor BA, Treacher DF, Turner RC. Homeostasis model assessment: insulin resistance and beta-cell function from fasting plasma glucose and insulin concentrations in man. Diabetologia 1985; 28: 412-419

13 Theodoraki A, Bouloux PM. Testosterone therapy in men. Menopause Int 2009; 15: 87-92

14 Friedewald WT, Levy RI, Fredrickson DS. Estimation of the concentration of low-density lipoprotein cholesterol in plasma, without use of the preparative ultracentrifuge. Clin Chem 1972; 18: 499-502

15 Kanauchi M. A new index of insulin sensitivity obtained from the oral glucose tolerance test applicable to advanced type 2 diabetes. Diabetes Care 2002; 25: 1891-1892

16 Yazici M, Sahin M, Bolu E, Uckaya G, Gok DE, Taslipinar A, Ozgurtas T, Kutlu M. Prediction of testosterone response to human chorionic gonadotrophin in idiopathic hypogonadotropic hypogonadism patients. J Natl Med Assoc 2009; 101: 71-76

17 Kapoor D, Goodwin E, Channer KS, Jones TH. Testosterone replacement therapy improves insulin resistance, glycaemic control, visceral adiposity and hypercholesterolaemia in hypogonadal men with type 2 diabetes. Eur J Endocrinol 2006; 154: 899-906

18 Marin P, Holmang S, Jonsson L, Sjostrom L, Kvist H, Holm G, Lindstedt $G$, Bjorntorp P. The effects of testosterone treatment on body composition and metabolism in middle-aged obese men. Int J Obes Relat Metab Disord 1992; 16: 991-997

19 Tripathy D, Shah P, Lakshmy R, Reddy KS. Effect of testosterone replacement on whole body glucose utilisation and other cardiovascular risk factors in males with idiopathic hypogonadotrophic hypogonadism. Horm Metab Res 1998; 30: 642-645
20 Singh AB, Hsia S, Alaupovic P, Sinha-Hikim I, Woodhouse L, Buchanan $T A$, Shen R, Bross R, Berman N, Bhasin S. The effects of varying doses of $\mathrm{T}$ on insulin sensitivity, plasma lipids, apolipoproteins, and C-reactive protein in healthy young men. J Clin Endocrinol Metab 2002; 87: 136-143

21 Boyanov MA, Boneva Z, Christov VG. Testosterone supplementation in men with type 2 diabetes, visceral obesity and partial androgen deficiency. Aging Male 2003; 6: 1-7

22 Naharci MI, Pinar M, Bolu E, Olgun A. Effect of testosterone on insulin sensitivity in men with idiopathic hypogonadotropic hypogonadism. Endocr Pract 2007; 13: 629-635

23 Smith MR, Lee H, Nathan DM. Insulin sensitivity during combined androgen blockade for prostate cancer. J Clin Endocrinol Metab 2006; 91: $1305-1308$

24 Kapoor D, Clarke S, Stanworth R, Channer KS, Jones TH. The effect of testosterone replacement therapy on adipocytokines and C-reactive protein in hypogonadal men with type 2 diabetes. Eur J Endocrinol 2007; 156: 595-602

25 Aydogdu A, Bolu E, Sonmez A, Tasci I, Haymana C, Acar R, Meric C, Taslipinar A, Ozgurtas T, Azal O. Effects of three different medications on metabolic parameters and testicular volume in patients with hypogonadotropic hypogonadism: 3-year experience. Clin Endocrinol (Oxf) 2013; 79: 243-251

26 Singh R, Artaza JN, Taylor WE, Gonzalez-Cadavid NF, Bhasin S. Androgens stimulate myogenic differentiation and inhibit adipogenesis in C3H 10T1/2 pluripotent cells through an androgen receptor-mediated pathway. Endocrinology 2003; 144: 5081-5088

27 Eiholzer U, Grieser J, Schlumpf M, l'Allemand D. Clinical effects of treatment for hypogonadism in male adolescents with Prader-LabhartWilli syndrome. Horm Res 2007; 68: 178-184

28 Rodriguez-Tolrà J, Torremadé Barreda J, del Rio L, di Gregorio S, Franco Miranda E. Effects of testosterone treatment on body composition in males with testosterone deficiency syndrome. Aging Male 2013; 16: 184-190

29 Giltay EJ, Haider A, Saad F, Gooren LJ. C-reactive protein levels and ageing male symptoms in hypogonadal men treated with testosterone supplementation. Andrologia 2008; 40: 398

30 Mazo EB, Gamidov SI, Iremashvili VV, Gasanov RV. Efficacy of phosphodiesterase inhibitors in the treatment of patients with organic erectile dysfunction: a comparative study. Urologia 2009; 40: 43-46

31 Oktenli C, Yesilova Z, Ozata M, Yaman H, Tuzun A, Dundar S, Sanisoglu SY, Musabak U, Erbil MK, Dagalp K. Gonadotropin treatment increases homocysteine levels in idiopathic hypogonadotropic hypogonadism: an indirect effect mediated by changes in body composition. J Endocrinol 2003; 179: 35-39

32 Hagenfeldt Y, Linde K, Sjoberg HE, Zumkeller W, Arver S. Testosterone increases serum 1,25-dihydroxyvitamin D and insulin-like growth factor-I in hypogonadal men. Int J Androl 1992; 15: 93-102

33 MacGillivray $M H$. Induction of puberty in hypogonadal children. J Pediatr Endocrinol Metab 2004; Suppl 4: 1277-1287

34 Liu L, Merriam GR, Sherins RJ. Chronic sex steroid exposure increases mean plasma growth hormone concentration and pulse amplitude in men with isolated hypogonadotropic hypogonadism. J Clin Endocrinol Metab 1987; 64: 651-656

35 Prior JC, Cox TA, Fairholm D, Kostashuk E, Nugent R. Testosteronerelated exacerbation of a prolactin-producing macroadenoma: possible role for estrogen. J Clin Endocrinol Metab 1987; 64: 391-394

36 Sodi $R$, Fikri R, Diver M, Ranganath $L$, Vora J. Testosterone replacementinduced hyperprolactinaemia: case report and review of the literature. Ann Clin Biochem 2005; 42: 153-159

37 Miner MM, Sadovsky R. Evolving issues in male hypogonadism: evaluation, management, and related comorbidities. Cleve Clin J Med 2007; 74 (Suppl 3): 38-46 